\title{
SUBDIAPHRAGMATIC HAEMATOCELE DUE TO PNEUMOPERITONEUM
}

BY

\author{
E. G. W. HOFFSTAEDT \\ From Holywood Hall Sanatorium, Wolsingham, County Durham
}

(RECEIVED FOR PUBlication MAY 16, 1951)

Artificial pneumoperitoneum (P.-P.) is a less risky collapse procedure than A.P., but there is evidence that P.-P. is not free from complications. Trivial as well as serious, and even fatal, complications have been reported.

No serious consequences of needle puncture of the bowel have been described, but small peritoneal effusions are a fairly frequent and usually harmless event, and transient gastro-intestinal disturbances sometimes interfere with the continuation of treatment.

Cohen (1948) published four serious cases of tuberculous ascites following P.-P., and he feels "that the development of ascites in the course of artificial pneumoperitoneum may be a grave complication which should be watched for." Another point is that fluid, developing under collapse treatment, might occasionally consist of blood, or might at least contain a proportion of blood.

Such complications as abdominal pneumocele (Wortman and Bass, 1949), scrotal pneumocele (Monto and Bradford, 1943 ; Banyai, 1946 ; Rogers and Garrett, 1947 ; Meltzer, 1948 ; Nagley, 1948), and inguinal hernia (Mitchell, Hiatt, McCain, Easom, and Thomas, 1947 ; Bennett, 1938 ; Nagley, 1948 ; McAuliffe and Douglass, 1949 ; Habeeb and Reiser, 1950 ; Thompson Evans, 1950) have usually been harmless and did not interfere with the continuation of the treatment.

Mediastinal emphysema (Banyai and Jurgens, 1939 ; Simmonds, 1946 ; Keers, 1948 ; Morrison, 1949 ; Small and Fremont, 1951) usually takes a harmless course unless it is complicated by a secondary pneumothorax. Pritchard (1947) had a fatal case of interstitial traumatic mediastinal emphysema where no air embolism could be found at necropsy. Accidental as well as spontaneous pneumothorax has been repeatedly described as a complication of P.-P. (Banyai and Jurgens, 1940 ; Rilance and Warring, 1941 ; Smith, 1943 ; Simmonds, 1946 ; Mitchell et al., 1947 ; Sita-Lumsden, 1949 ; Ross and Farber, 1951 ; Vannitelli, Woodruff, Mueller, and Howard, 1949 ; Repa and Jacobson, 1951).

The most serious complication of P.-P. is air embolism, which, though sometimes of a milder character (Simmonds, 1946 ; Keers, 1948 ; Habeeb and Reiser, 
1950 ; Netzer, 1951), is nevertheless the most frequent cause of death (Simon, 1925 ; Trimble and Wardrip, 1937 ; Harrell, 1940 ; Warring and Thomas, 1940 ; Rilance and Warring, 1941 and 1944 ; Roche and Giron, 1944 ; Aslett and Jarman, 1945 ; Simmonds, 1946 ; Mitchell et al., 1947 ; Bailey, 1948 ; Trimberg, 1948 ; Foy Wu and Neptune, 1951 ; Sita-Lumsden and Elphinstone, 1950).

An apparently rare, though not at all harmless, complication of P.-P. is intraperitoneal haemorrhage. Searching the literature for reports of this complication I only came across five published cases. Cotton Cornwall and Patridge (1947) published two cases; one was of a fatal peritoneal haemorrhage due to puncture of an omental vein, another probable case of intraperitoneal haemorrhage, which eventually recovered after some very critical days. Trimble, Eaton, Crenshaw, and Gourley (1948) report a case of haemorrhage in the spleen, necessitating surgical treatment. This patient recovered. Habeeb and Reisner (1950) mention a case of puncture of the inferior epigastric artery without giving any details. Larkin and Phillips (1951) described a case of severe, massive, intraperitoneal haemorrhage with the loss of 5 litres of blood into the peritoneal cavity ; after repeated blood transfusions a laparotomy was performed and the blood was removed by suction, but there was no clue to the origin of the bleeding. This patient eventually recovered after further postoperative blood transfusions. The authors assume that the haemorrhage came either from a punctured blood vessel in the abdominal wall just beneath the parietal peritoneum or from a ruptured vascular adhesion, as the patient complained of a "tearing sensation" in the abdomen before the onset of pain after the refill. All these cases had severe haemorrhages: one case was fatal, another (puncture of the epigastric artery) possibly fatal, two required laparotomy, and one was seriously ill. There is no doubt, therefore, that intra-abdominal haemorrhage, though rare, is a serious complication of P.-P.

The potential danger inherent in any internal haemorrhage, and the diagnostic difficulties encountered in a completely asymptomatic case of extraperitoneal haemorrhage due to P.-P. treatment, seem to justify the publication of the following rather unusual case.

\section{CASE Report}

A man of 21 had a P.P. induced in this sanatorium in November, 1949. He had a right phrenic crush in February, 1950. By August, 1950, the right diaphragm had gradually recovered its mobility. With weekly refills, amounting to 800 to $1,000 \mathrm{ml}$., a good subdiaphragmatic airspace could be maintained with the right diaphragm . kept at the level of the eighth to the ninth posterior rib (Fig. 1). The patient was fit and working for three hours a day in our laboratory, when routine screening on January 20, 1951, showed a conspicuous, dense, rounded shadow on top of the liver. The patient did not complain of pain or of abdominal discomfort and he had no pain on palpation or on pressure. No mass could be felt on examination. A radiograph taken three days later (Fig. 2) revealed a bag or cyst-like rounded shadow with a semicircular lower pole just above the upper contour of the liver. Screening in different positions showed a clearly defined pear-shaped shadow lying anteriorly between the right diaphragm and the liver, and situated in the anterior sulcus. A lateral film (Fig. 3) showed the antero-subdiaphragmatic position of the shadow. The differential diagnosis between cyst, herniation, or diverticulum was in favour of some sort of cyst, as a barium swallow with tilting of the patient in various directions failed to show a connexion of 


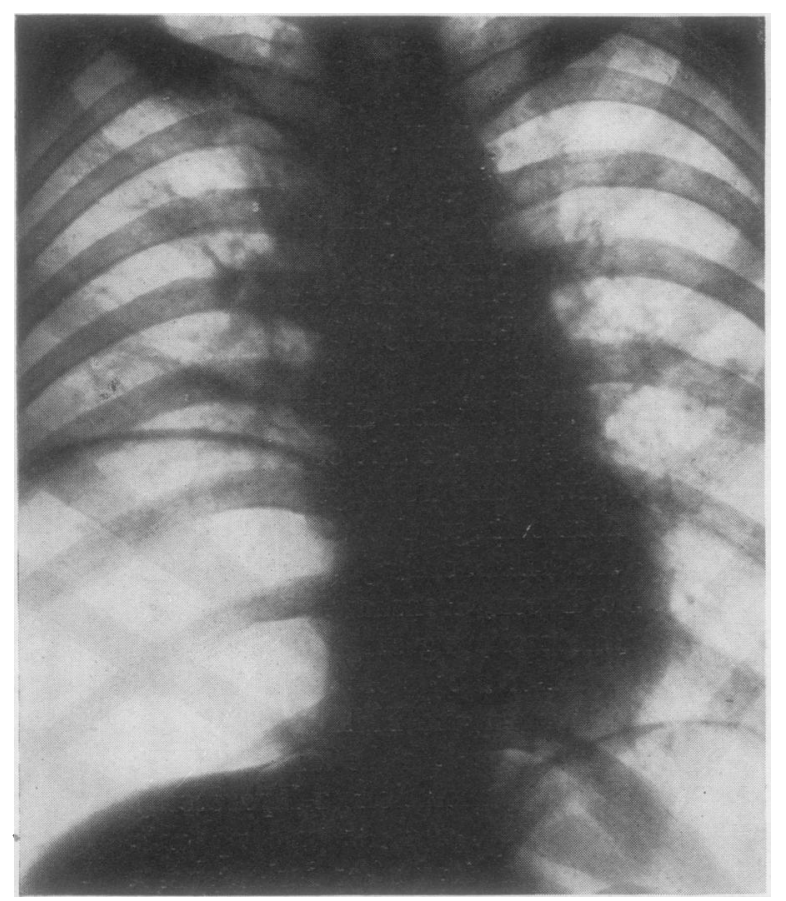

FIG. 1.

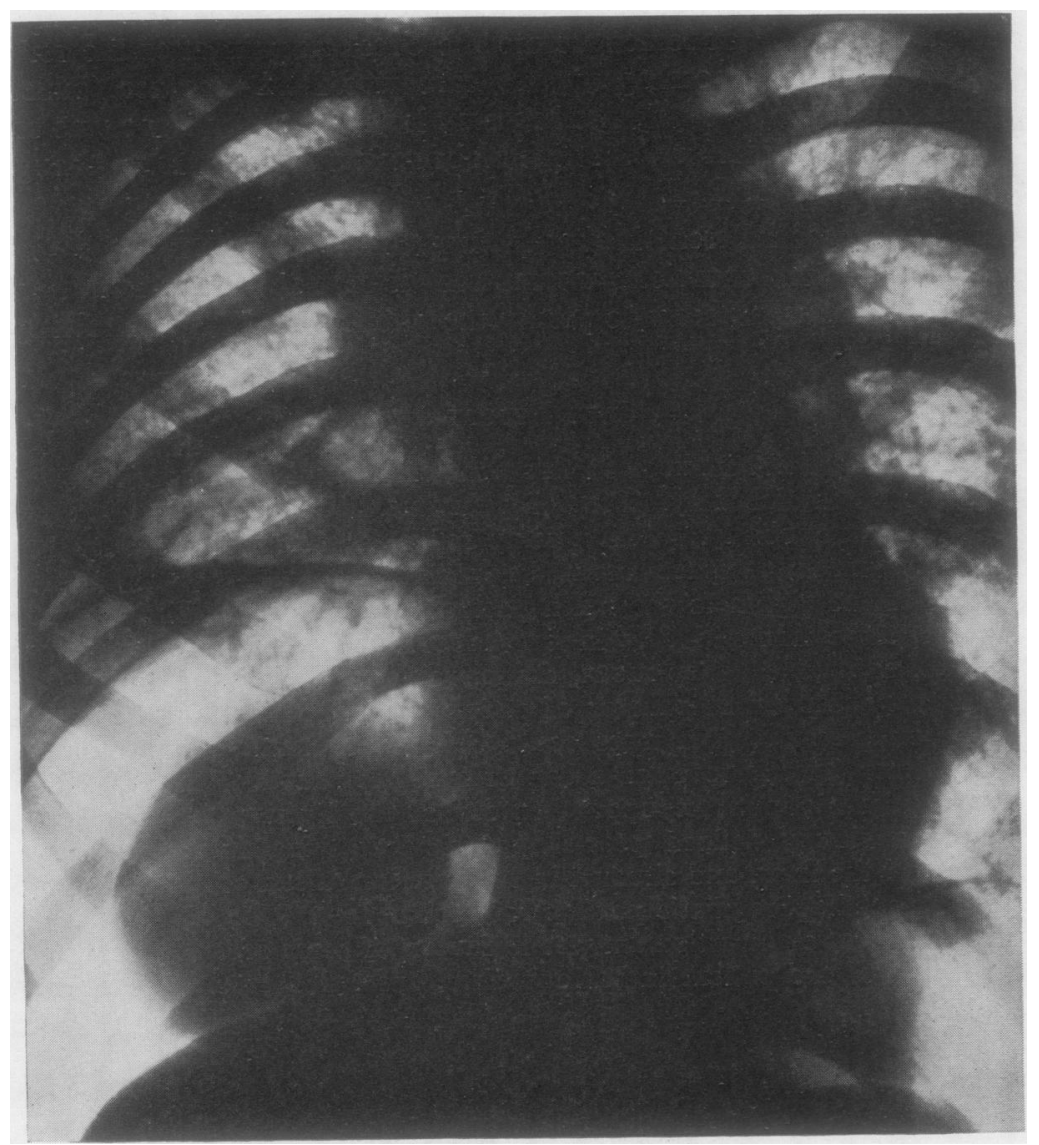

FIG. 2. 


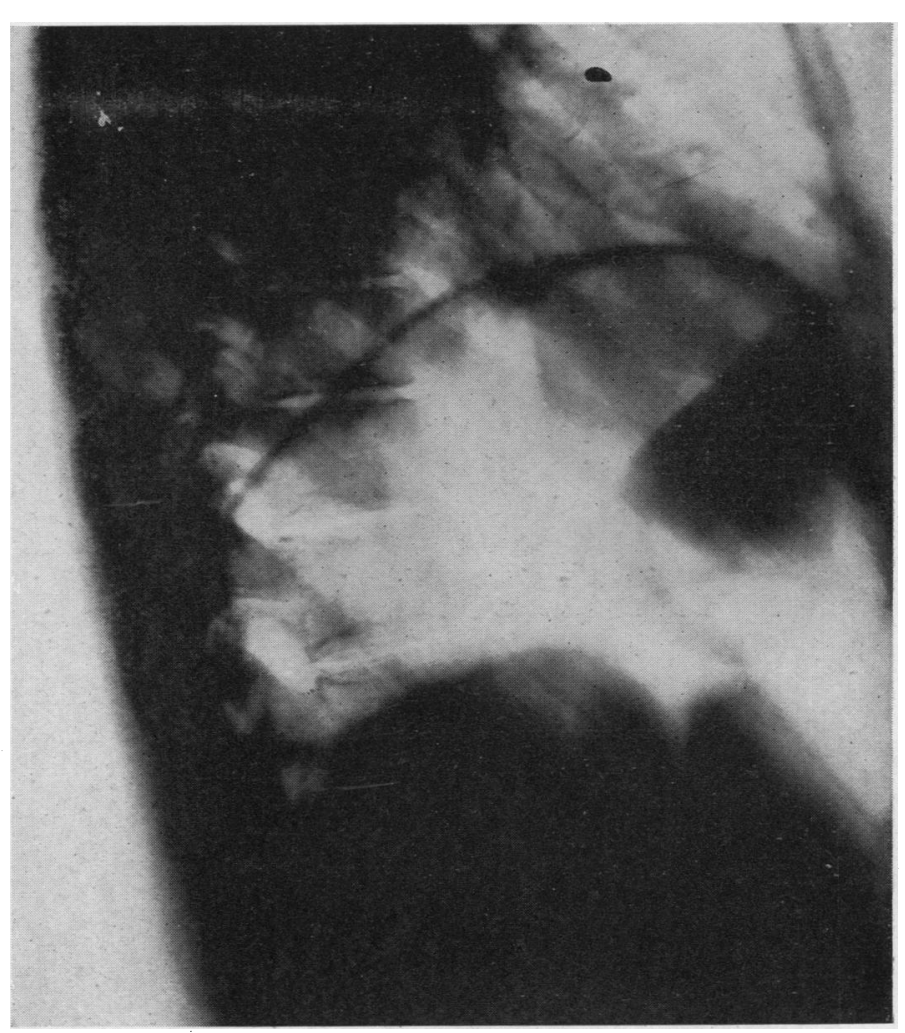

Fig. 3.

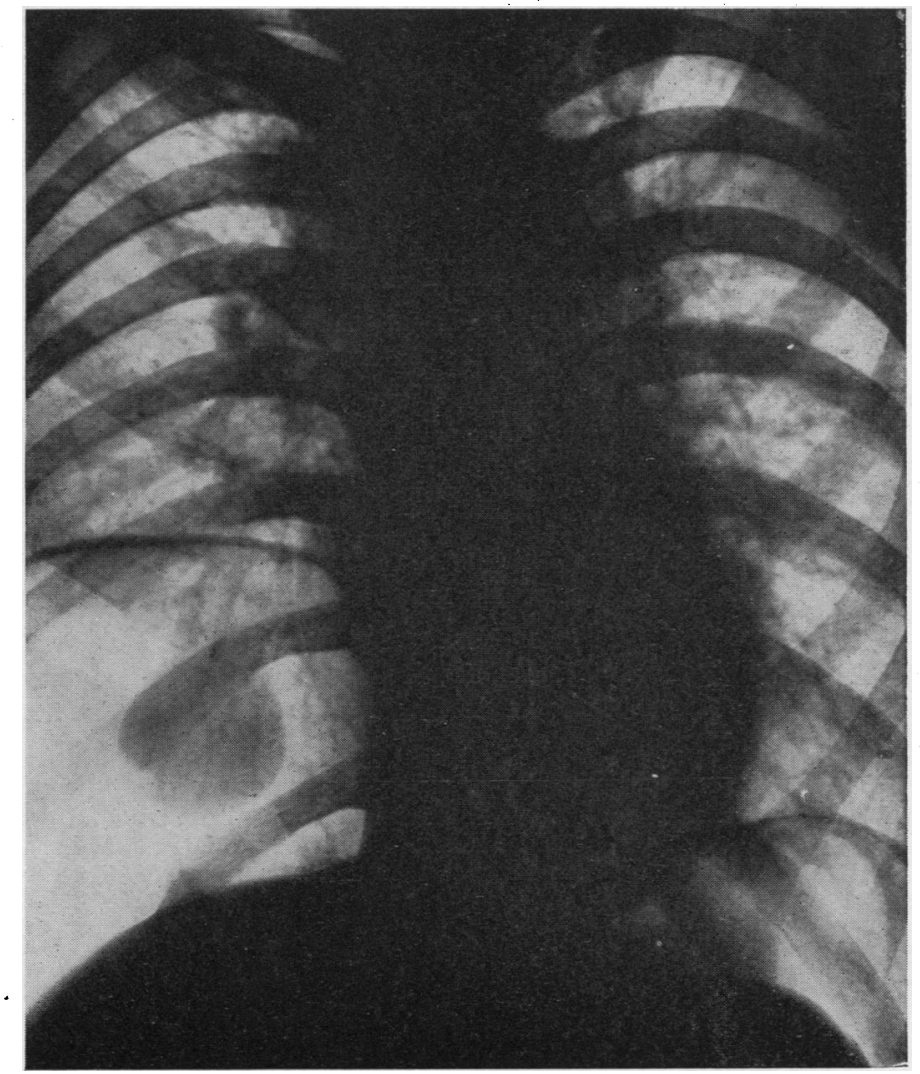

FIG. 4 . 
the shadow with either the oesophagus or the stomach. The possibility of a haematoma was thought of, but, as no definite diagnosis had been arrived at, the films were shown at a meeting of chest physicians of the Region. Here the diagnosis of an encysted haematoma was offered. In order to clinch the diagnosis a peritoneoscopy was performed by Mr. J. A. Simpson on February 9, 1951. This is what he saw:

"There was a smooth, pear-shaped swelling projecting backwards from the anterior part of the diaphragm. It had a bluish colour and appeared cystic. The appearance suggested that it was an extraperitoneal collection of blood."

Apart from a transient traumatic pneumothorax following the peritoneoscopy the patient made an uneventful recovery and the P.-P. was continued. The film of April 18, before the patient's discharge from the sanatorium (Fig. 4), showed diminution in size of the shadow. The patient is now fit and the haematoma is likely to resorb completely in due course.

In this case the haemorrhage was probably due to a puncture of the diaphragm. The accident has been reconstructed with the aid of trick photography (Fig. 5) in order to show what probably happened.*

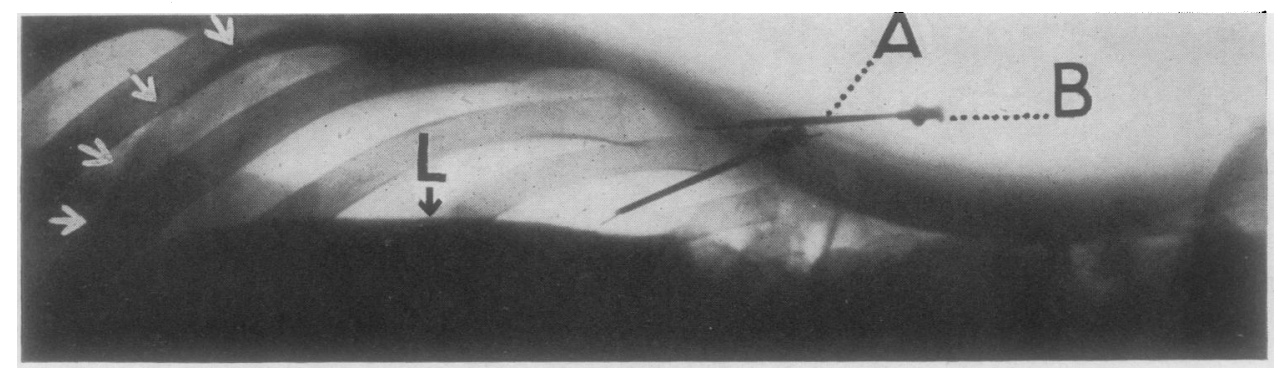

FIG. 5.

The patient was placed in a semi-lateral recumbent position and radiographs were taken in an antero-posterior direction. The right side being uppermost, one could see the elevated right diaphragm (marked by arrows), the liver shadow (L), and the subdiaphragmatic air space. Our routine technique of P.-P. refills, once a good air space has been established, is to place the patient in a semi-lateral posture with the costal margin, on the side of the phrenic crush, uppermost. The needle (A) was inserted one to two fingers below the costal margin, pointing downwards in a blunt angle. If correctly placed, the needle point will lie in the free air space. In contrast to the correct insertion (A), in our case the needle must have been pointed upwards (B), and its point has perforated the peritoneal lining of the diaphragm, pricked the lower surface of the diaphragm, and so damaged a blood vessel. The blood, oozing from the puncture hole, has separated the peritoneum from the diaphragm and has collected between the diaphragm and the peritoneum. The latter has formed the membrane of the haematocele.

While puncture of an omental vein or of a vessel in the abdominal wall is a misadventure which might happen, it should be avoided by correct technique. If the subdiaphragmatic route, described above, is used, care must also be taken not to scratch the diaphragm from below.

* In order to give the desired effect on the film the needles have been stuck on to the skin by transparent tape under control of the screen. The downward tilt of needle $A$ is rather exaggerated; a slight pressure on needle $B$ will push the point towards the diaphragm. 


\section{SUMMARY}

After surveying the literature concerning the complications of P.-P., with particular reference to intra-abdominal haemorrhage, a case of extraperitoneal, subdiaphragmatic haematocele is described and illustrated. An attempt has been made to explain and to illustrate the origin of the bleeding and to show how to avoid such accidents.

My thanks are due to Dr. J. W. Gray, Medical Superintendent of Holywood Hall Sanatorium, for his permission to publish the case.

\section{REFERENCES}

Aslett, E., and Jarman, T. F. (1945). Lancet, 1, 304.

Bailey, W. H. (1948). Amer. Rev. Tuberc., 57, 621.

Banyai, A. L. (1946). Pneumoperitoneum Treatment. St. Louis.

— and Jurgens, G. H. (1939). J. thorac. Surg., 8, 329. (1940). Amer. Rev. Tuberc., 42, 688.

Bennett, E. S. (1938). J. Lancet, 58, 187.

Cohen, R. C. (1948). Lancet, 2, 1006.

Cornwall, V. Cotton, and Patridge, W. H. (1947). Tubercle, Lond., 28, 164.

Habeeb, W. J., and Reiser, H. G. (1950). Amer. Rev. Tuberc., 61, 323.

Harrell, C. L. (1940). Dis. Chest, 6, 273.

Keers, R. Y. (1948). Brit. J. Tuberc., 42, 58.

Larkin, J. C., Jr., and Phillips, S. (1951). Amer. Rev. Tuberc., 63, 116.

McAuliffe, W. J., and Douglass, R. (1949). Ibid., 60, 524.

Meltzer, H. (1948). Brit. J. Tuberc., 42, 70.

Mitchell, R. S., Hiatt, J. S., Jr., McCain, P. P., Easom, H. F., and Thomas, C. D. (1947). Amer. Rev. Tuberc., 55, 306.

Monto, R. W., and Bradford, H. A. (1943). Ibid., 47, 537.

Morrison, J. B. (1949). Brit. J. Tuberc., 43, 18.

Nagley, M. M. (1948). Ibid., 42, 17.

Netzer, S. (1951). Amer. Rev. Tuberc., 63, 62.

Pritchard, E. K. (1947). Personal communication.

Repa, J. J., and Jacobson, H. R. (1951). Amer. Rev. Tuberc., 63, 587.

Rilance, A. B., and Warring, F. C. (1941). Ibid., 44, 323.

- (1944). Ibid., 49, 353 .

Roche, G., and Giron, J. (1944). Rev. Tuberc., Paris, 9, 115.

Rogers, W. N., and Garrett, J. V. (1947). Brit. J. Tuberc., 41, 70.

Ross, J., and Farber, J. E. (1951). Amer. Rev. Tuberc., 63, 67.

Simmonds, F. A. H. (1946). Lancet, 1, 530.

Simon, T. (1925). Med. Klinik, 21, 589.

Sita-Lumsden, E. G. (1949). Thorax, 4, 147. and Elphinstone, R. H. (1950). Brit. med. J., 1, 166.

Small, M. J., and Fremont, R. E. (1951). Amer. Rev. Tuberc., 63, 591.

Smith, C. N. (1943). Brit. med. J., 2, 404.

Thompson Evans, E. W. (1950). Brit. J. Tuberc., 44, 67.

Trimble, H. G., Eaton, J. L., Crenshaw, G. L., and Gourley, I. (1948). Amer. Rev. Tuberc., 57, 433. - and Wardrip, B. H. (1937). Ibid., 36, 111.

Vannitelli, S. A., Woodruff, C. E., Mueller, E. E., and Howard, W. L. (1949). Ibid., $60,794$.

Warring, F. C., and Thomas, R. M. (1940). Ibid., 42, 682.

Wortman, H. C., and Bass, H. E. (1949). Ibid., 60, 520.

Wu, J. Foy, and Neptune, W. B. (1951). Ibid., 63, 710. 